Supporting Information

\title{
Mechanisms of Hydrogen Evolution Reaction in Two-Dimensional Nitride MXenes using In Situ X-Ray Absorption Spectroelectrochemistry
}

Abdoulaye Djire ${ }^{1,2 *}$, Hanyu Zhang, ${ }^{1,}$ Benjamin J. Reinhart, ${ }^{3} \mathrm{O}$. Charles Nwamba, ${ }^{1}$ and Nathan R. Neale $^{1 *}$

${ }^{1}$ Chemistry and Nanoscience Center, National Renewable Energy Laboratory, Golden, CO, 80401, USA

${ }^{2}$ Artie McFerrin Department of Chemical Engineering, Texas A\&M University, 3122 TAMU, College Station, TX 77843, USA

${ }^{3}$ Advanced Photon Source, Argonne National Laboratory, Argonne, Illinois 60439, USA

Corresponding Authors: *adjire@tamu.edu,*nathan.neale@nrel.gov 


\section{Experimental Methods}

\section{Materials Synthesis}

The precursor $\mathrm{Ti}_{4} \mathrm{AlN}_{3}$ MAX phase, exfoliated $\mathrm{Ti}_{4} \mathrm{~N}_{3} \mathrm{~T}_{\mathrm{x}}$ MXene, and mixed-transition metal nitride $\mathrm{M}-\mathrm{Ti}_{4} \mathrm{~N}_{3} \mathrm{~T}_{\mathrm{x}} \mathrm{MXenes}$ were synthesized according to the procedure used in our prior publication. ${ }^{1}$

\section{In-Situ X-Ray Absorption Spectroscopy}

In-situ XAS measurements were performed in a custom-made in-situ electrochemical cell as shown in Figure $\mathrm{S} 1$. The working electrodes $\left(\mathrm{Ti}_{4} \mathrm{AlN}_{3} \mathrm{MAX}\right.$, pristine $\mathrm{Ti}_{4} \mathrm{~N}_{3} \mathrm{~T}_{\mathrm{x}} \mathrm{MXene}$, and $\mathrm{M}-$ $\mathrm{Ti}_{4} \mathrm{~N}_{3} \mathrm{~T}_{\mathrm{x}}$ MXenes) were prepared by membrane filtration process using an ITO substrate. ${ }^{1-3}$ The reference and counter electrodes were $\mathrm{Ag} / \mathrm{AgCl}$ and graphite rod, respectively. XAS measurements were performed in $0.5 \mathrm{M} \mathrm{H}_{2} \mathrm{SO}_{4}$ electrolytic solution. The electrolyte solution was purged with $\mathrm{N}_{2}$ (99.998\%) for half an hour prior to adding into the in-situ electrochemical reaction cell. XAS measurements were performed in fluorescence mode at the multi-purpose beamline for spectroscopy, 12-BM at APS. A defined beam size of $0.5 \times 0.8 \mathrm{~mm}^{2}$ using slits and an incident photon flux of $\sim 10^{11}$ photons $\mathrm{s}^{-1}$ were used. For each material, first, we collected XAS spectra on the dried and wet forms (at the open circuit potential) using a Biologic potentiostat SP300. Prior to the potential-hold XAS measurements, cyclic voltammograms and linear sweep voltammograms were acquired for each sample to ensure that the electrochemical features were consistent with previous work. ${ }^{1}$ Next, we collected spectra at four (4) different potentials within the voltage window. After that, we measured XAS at $-0.5 \mathrm{~V}$ vs. $\mathrm{Ag} / \mathrm{AgCl}$, which is in the HER activity region for some but not all of the samples. During each measurement, the nitride MXene material in the in-situ electrochemical cell was held at a constant potential for 15 min prior to the XAS measurements and held at this potential during the XAS data acquisition. Each spectrum 
shown in Figure S2a-d is the average of three (3) scans or spectra. Additionally, we collected XAS spectra for bare metal foils as references as shown in Figure S2a-d.

\section{In-situ X-Ray Absorption Spectroelectrochemical Cell}

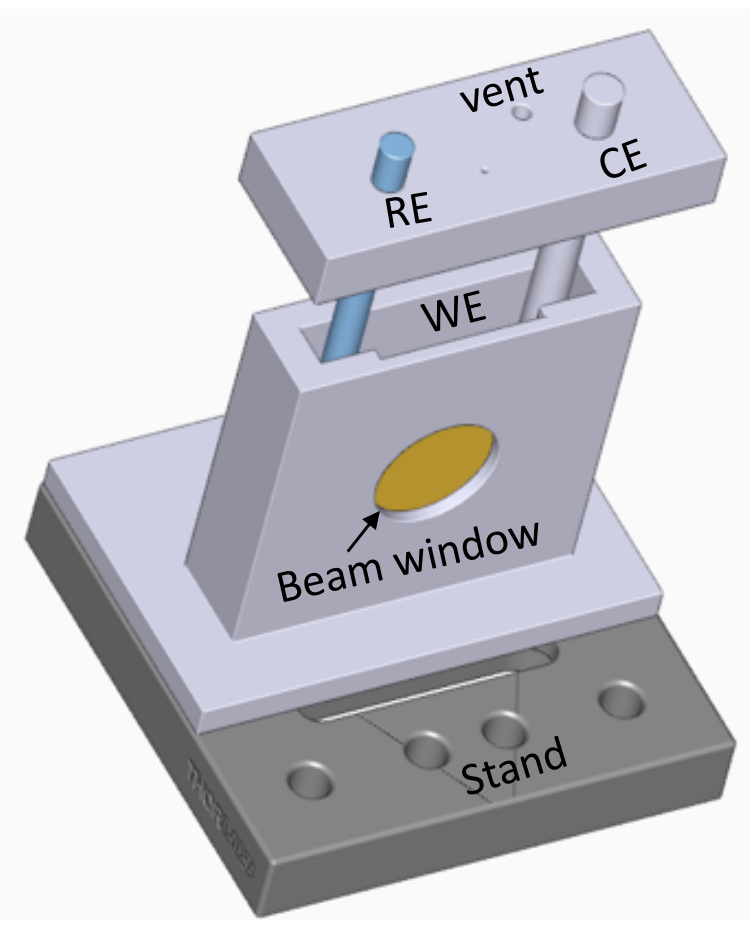

Figure S1. In-situ electrochemical cell for the x-ray absorption spectroelectrochemical experiments. $\mathrm{RE}$ and $\mathrm{CE}$ are the reference electrode $(\mathrm{Ag} / \mathrm{AgCl}, 6 \mathrm{~mm})$ and counter electrode (graphite rod, $7.5 \mathrm{~cm}$ long and $6 \mathrm{~mm}$ in diameter), respectively. The working electrode (WE) was comprised of exfoliated $\mathrm{Ti}_{4} \mathrm{~N}_{3} \mathrm{~T}_{\mathrm{x}}$ and $\mathrm{M}-\mathrm{Ti}_{4} \mathrm{~N}_{3} \mathrm{~T}_{\mathrm{x}}$ MXenes. Thin coated nitride MXenes on ITO working electrodes ( $\sim 100 \mathrm{~nm}$ thick) were mounted near the window of the in-situ cell. The window was covered with Kapton tape. We observed no scattering from the electrolyte during the XAS measurements. 


\section{In-situ X-Ray Absorption Spectroelectrochemical Characterization}

We used in-situ x-ray absorption spectroscopy (XAS) technique to elucidate the mechanisms of hydrogen evolution reaction (HER) activity in two-dimensional (2D) nitride MXenes. Figure S2 shows the normalized fluorescence XAS spectra for the $\mathrm{Ti}_{4} \mathrm{AlN}_{3}$ MAX phase, exfoliated $\mathrm{Ti}_{4} \mathrm{~N}_{3} \mathrm{~T}_{\mathrm{x}}$ MXene, and mixed-metal $\mathrm{Mn}-\mathrm{Ti}_{4} \mathrm{~N}_{3} \mathrm{~T}_{\mathrm{x}}, \mathrm{Mo}-\mathrm{Ti}_{4} \mathrm{~N}_{3} \mathrm{~T}_{\mathrm{x}}$, and $\mathrm{Cr}-\mathrm{Ti}_{4} \mathrm{~N}_{3} \mathrm{~T}_{\mathrm{x}}$ nitride MXenes. Each spectrum shown in Figure S2a-d is the average of three (3) scans or spectra. Additionally, we

collect XAS spectra for bare metal foils as references as shown in Figure S2a-d. The spectra in Figure S2a-d show the absorption k-edge energies for $\mathrm{Ti}, \mathrm{Mn}, \mathrm{Mo}$, and $\mathrm{Cr}$ metals and are normalized to the initial absorption energy, $E_{0}$. The k-edge absorption energy $\mu$ (E) shown here for the $\mathrm{Ti}, \mathrm{Mn}, \mathrm{Mo}$, and $\mathrm{Cr}$ metals are directly proportional to the ratio of the fluorescence intensity leaving the material, $\mathrm{I}_{\mathrm{f}}$, and the initial intensity going into the material, $\mathrm{I}_{0}$, according to the following equation: ${ }^{4}$

$$
\mu(\mathrm{E}) \propto \mathrm{I}_{\mathrm{f}} / \mathrm{I}_{0}
$$

The intensity of the $\mathrm{I}_{0}$ was measured by using an ion chamber. The XAS spectra in Figure S2a-d are comprised of the x-ray absorption near-edge structure (XANES) and the extended x-ray absorption fine structure (EXAFS) and contain information on the changes in the electronical and structural properties in the nitride MXenes during electrochemical performance and catalytic HER activity. ${ }^{4}$ 

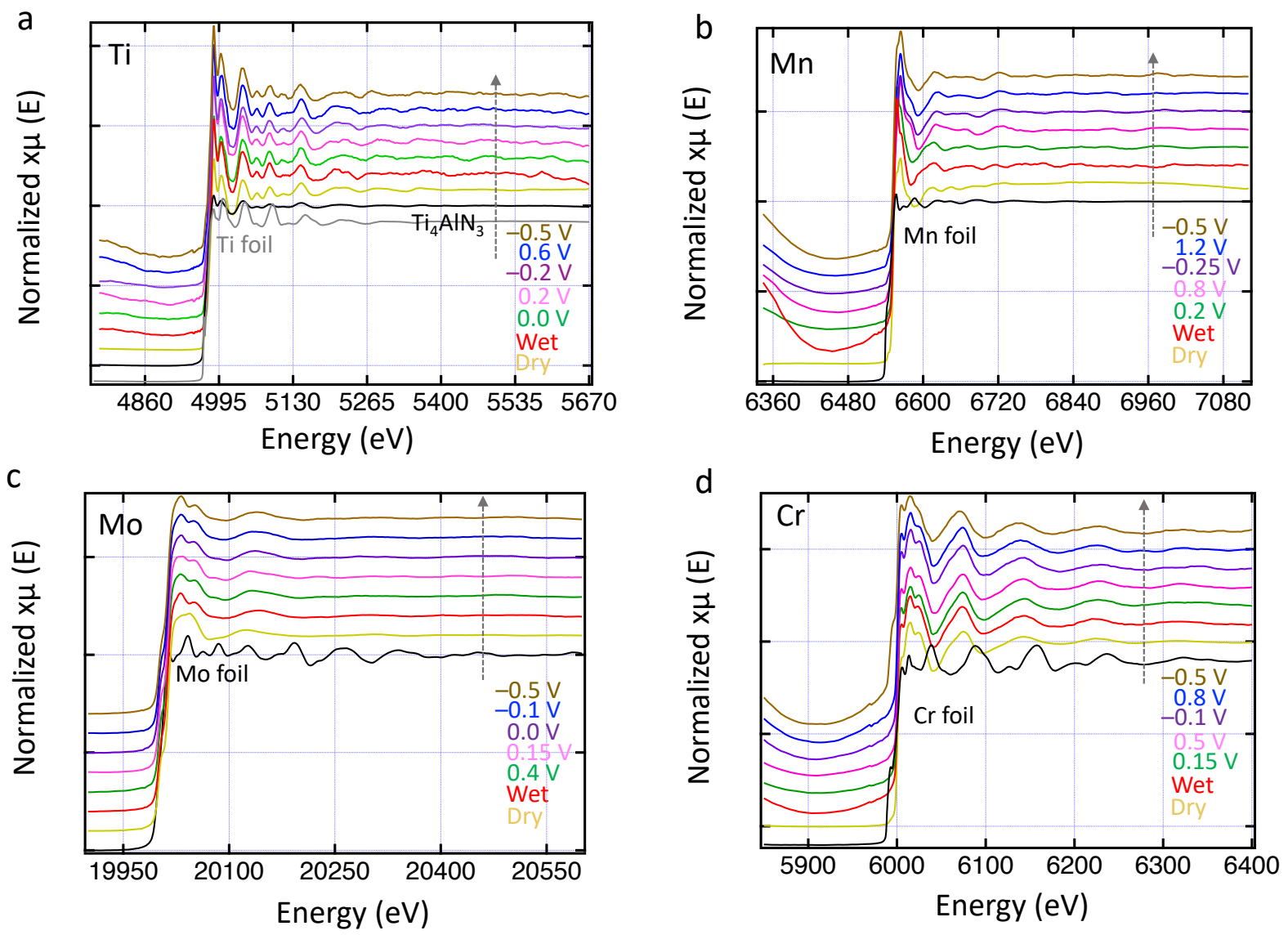

Figure S2. Normalized $\mathrm{x}$-ray absorption spectroscopy (XAS) data for (a) pristine $\mathrm{Ti}_{4} \mathrm{~N}_{3} \mathrm{~T}_{\mathrm{x}},(\mathrm{b}) \mathrm{Mn}$ $\mathrm{Ti}_{4} \mathrm{~N}_{3} \mathrm{~T}_{\mathrm{x}}$, (c) Mo- $\mathrm{Ti}_{4} \mathrm{~N}_{3} \mathrm{~T}_{\mathrm{x}}$, and (d) $\mathrm{Cr}_{-} \mathrm{Ti}_{4} \mathrm{~N}_{3} \mathrm{~T}_{\mathrm{x}}$ MXenes, showing the Ti, Mn, Mo, and Cr k edge energy, respectively. First, we collected XAS spectra for dry and wet samples, then, under operating conditions at different potentials in $0.5 \mathrm{M} \mathrm{H}_{2} \mathrm{SO}_{4}$ electrolytic solution. For the spectra collected under operating conditions, the pristine $\mathrm{Ti}_{4} \mathrm{~N}_{3} \mathrm{~T}_{\mathrm{x}} \mathrm{MXene}$ and $\mathrm{M}-\mathrm{Ti}_{4} \mathrm{~N}_{3} \mathrm{~T}_{\mathrm{x}} \mathrm{MXenes}$ were held at a constant potential for 15 min before the XAS measurement and held at the set potential while we collected the XAS spectra. The XAS spectrum for the precursor $\mathrm{Ti}_{4} \mathrm{AlN}_{3} \mathrm{MAX}$ phase is also shown (black spectrum in (a)). Additionally, we collected XAS spectra for bare metal foils as references as shown in (a-d). For all the materials, the spectrum (brown color) for the potential hold experiment at $-0.5 \mathrm{~V}$ versus $\mathrm{Ag} / \mathrm{AgCl}(\mathrm{V})$ is used to probe the HER XAS. We used $\mathrm{Ag} / \mathrm{AgCl}$ and graphite rod as reference and counter electrodes, respectively. 

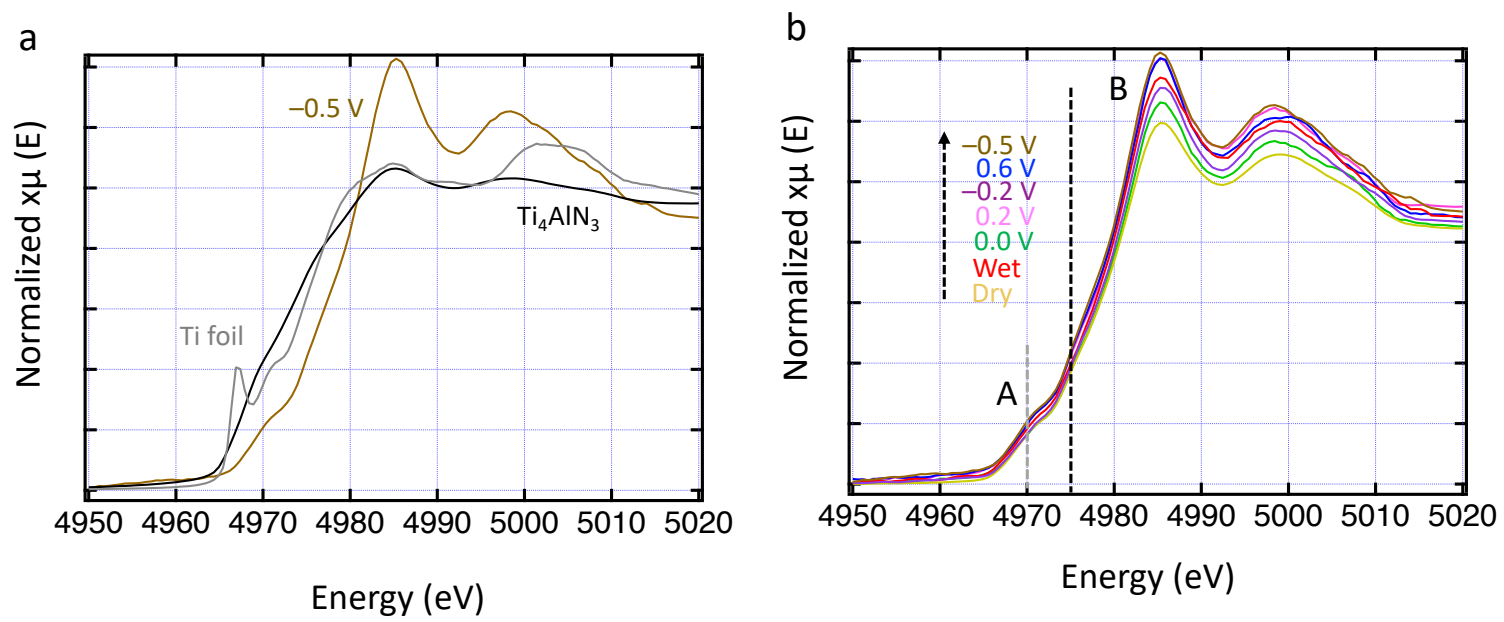

Figure S3. Normalized x-ray absorption near edge structure (XANES) for overlayed normalized XANES spectra for (a) Ti4 $\mathrm{AlN}_{3}$ MAX phase (grey), dry (gold spectrum), and $-0.5 \mathrm{~V}$ vs. RHE (V) (brown), and for (b) different potentials in $0.5 \mathrm{M} \mathrm{H}_{2} \mathrm{SO}_{4}$ electrolyte for pristine $\mathrm{Ti}_{4} \mathrm{~N}_{3} \mathrm{~T}_{\mathrm{x}}$. The grey and black dashed lines denote the pre-edge and edge energies, respectively. We used $\mathrm{Ag} / \mathrm{AgCl}$ and graphite rod as reference and counter electrodes, respectively. 

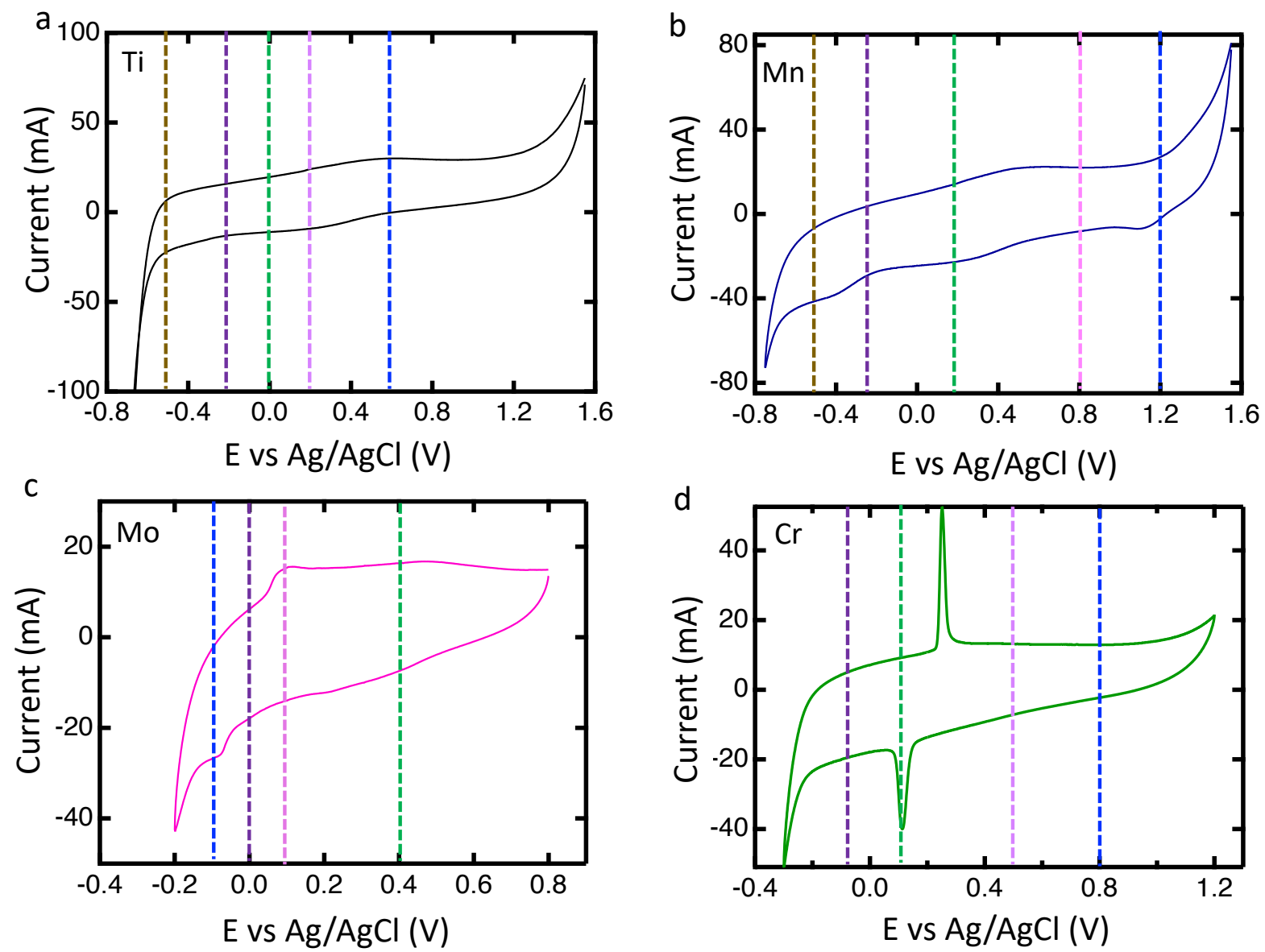

Figure S4. Cyclic voltammograms for (a) $\mathrm{Ti}_{4} \mathrm{~N}_{3} \mathrm{~T}_{\mathrm{x}}$ (black), (b) $\mathrm{Mn}-\mathrm{Ti}_{4} \mathrm{~N}_{3} \mathrm{~T}_{\mathrm{x}}$ (blue), (c) $\mathrm{Mo}_{-} \mathrm{Ti}_{4} \mathrm{~N}_{3} \mathrm{~T}_{\mathrm{x}}$ (pink), and (d) $\mathrm{Cr}_{-} \mathrm{Ti}_{4} \mathrm{~N}_{3} \mathrm{~T}_{\mathrm{x}}$ (green) in $0.5 \mathrm{M} \mathrm{H}_{2} \mathrm{SO}_{4}$ electrolyte at $50 \mathrm{mV} \mathrm{s}^{-1}$ adapted from reference.

${ }^{1}$ The in-situ XAS measurements were taken at the dashed lines shown in the voltammograms. The brown dashed line at $-0.5 \mathrm{~V}$ in panels a and $\mathrm{b}$ used for the HER XAS measurement is outside of the voltage window for $\mathrm{Cr}-$ and $\mathrm{Mo}-\mathrm{Ti}_{4} \mathrm{~N}_{3} \mathrm{~T}_{\mathrm{x}} \mathrm{MXenes}$ (panels $\mathrm{c}$ and d). 


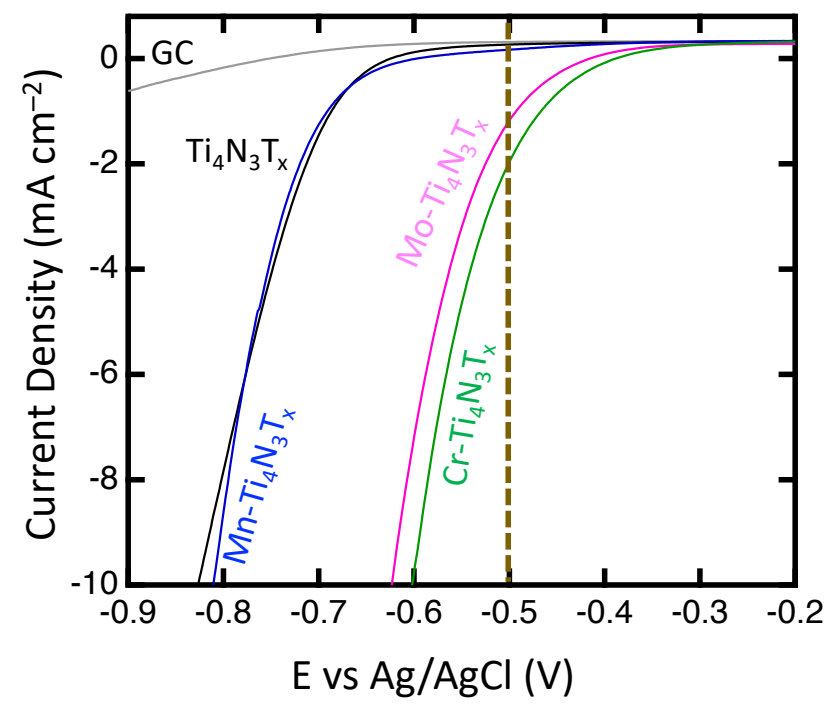

Figure S5. Linear sweep voltammetry for bare glassy carbon (grey), exfoliated $\mathrm{Ti}_{4} \mathrm{~N}_{3} \mathrm{~T}_{\mathrm{x}}$ MXene

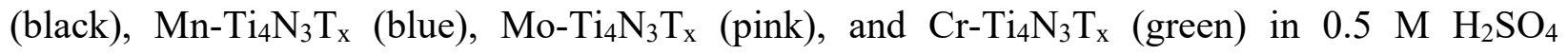
electrolyte solution at $5 \mathrm{mV} \mathrm{s}^{-1}$ adapted from reference. ${ }^{1}$ The brown dashed line indicates the potential used for the in-situ XAS measurement taken at the HER region for the Mo- $\mathrm{Ti}_{4} \mathrm{~N}_{3} \mathrm{~T}_{\mathrm{x}}$ and $\mathrm{Cr}-\mathrm{Ti}_{4} \mathrm{~N}_{3} \mathrm{~T}_{\mathrm{x}}$ samples. 

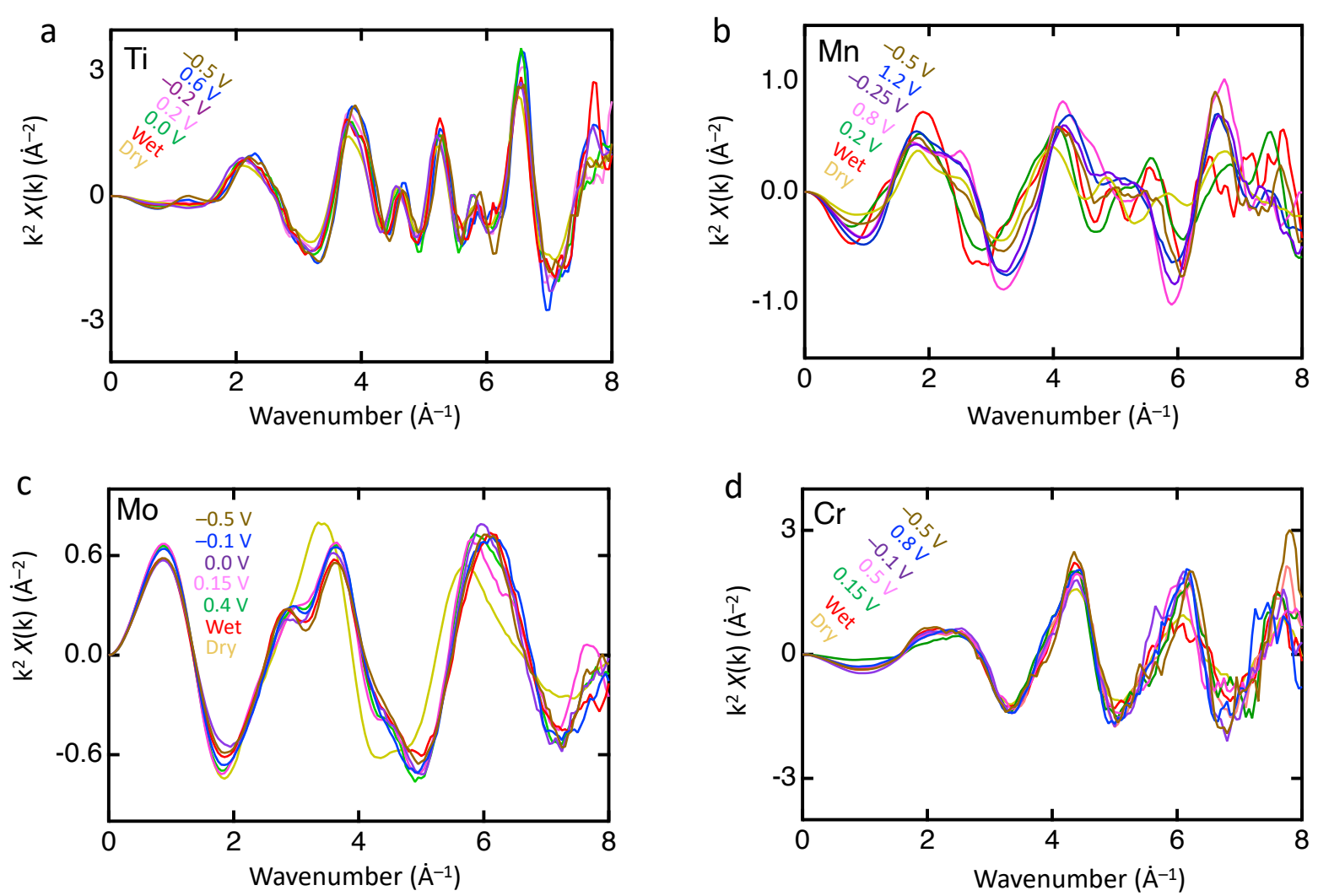

Figure S6. K-space spectra for dry (gold spectrum), wet (red spectrum) and different potentials in $0.5 \mathrm{M} \mathrm{H}_{2} \mathrm{SO}_{4}$ electrolyte for (a) pristine $\mathrm{Ti}_{4} \mathrm{~N}_{3} \mathrm{~T}_{\mathrm{x}}$, (b) $\mathrm{Mn}^{-} \mathrm{Ti}_{4} \mathrm{~N}_{3} \mathrm{~T}_{\mathrm{x}}$, (c) $\mathrm{Mo}^{-} \mathrm{Ti}_{4} \mathrm{~N}_{3} \mathrm{~T}_{\mathrm{x}}$, and (d) $\mathrm{Cr}-$ $\mathrm{Ti}_{4} \mathrm{~N}_{3} \mathrm{~T}_{\mathrm{x}}$ MXenes. We used $\mathrm{Ag} / \mathrm{AgCl}$ and graphite rod as reference and counter electrodes, respectively. We used a $\mathrm{K}$ weight of 2 . 


\section{In-situ Extended X-Ray Absorption Fine Structure}

The EXAFS spectra for the pristine exfoliated $\mathrm{Ti}_{4} \mathrm{~N}_{3} \mathrm{~T}_{\mathrm{x}}$ nitride MXene were fitted to the EXAFS equation using FEFF and IFEFFIT in Artemis software. ${ }^{4}$

$$
\chi(k)=S_{0}^{2} \sum_{i} N_{i} \frac{\left|f_{i}(k)\right|}{k R_{i}^{2}} e^{\left(-2 \sigma_{i}^{2} k^{2}\right)} e^{\left(-2 R_{i} / \lambda(k)\right)} \sin \left(2 k R_{i}+2 \delta_{i}+\varphi_{i}\right)
$$

Where $\mathrm{S}_{0}{ }^{2}$ is the amplitude reduction factor, $\mathrm{N}_{\mathrm{i}}$ is the number of scattering atoms, $\mathrm{f}_{\mathrm{i}}(\mathrm{k})$ is the scattering amplitude, $\mathrm{R}_{\mathrm{i}}$ is the distance from the central atom to the scattering atom, the exponent terms account for the disorder in the position of the atoms and scattered photoelectron vertically over a short distance, $\delta_{\mathrm{i}}$ is the phase shift undergone by the photoelectron at the central atom, and $\varphi_{\mathrm{i}}$ is the phase shift undergone by the photoelectron when it bounces off the scattering atom. ${ }^{4}$

Table S1. Fitting parameters from the IFFEF simulation from Artemis software for the pristine exfoliated $\mathrm{Ti}_{4} \mathrm{~N}_{3} \mathrm{~T}_{\mathrm{x}}$ MXene at different conditions, $\mathrm{R}$-factor $<0.03$.

\begin{tabular}{l|l|l|l|l}
\hline Electrode & $\begin{array}{l}\text { Scattering path \& } \\
\mathbf{N}\end{array}$ & \multicolumn{1}{|c|}{$\begin{array}{c}\text { Amplitude } \\
\mathbf{S}_{\mathbf{0}}^{\mathbf{2}}\end{array}$} & \multicolumn{1}{|c|}{$\begin{array}{c}\text { Bond strength } \\
\left(\boldsymbol{\sigma}^{\mathbf{2}}\right)\end{array}$} & \multicolumn{1}{|c|}{ Distance from Ti R } \\
\hline Dry & Ti-N (3) & 0.703 & 0.00182 & 2.06922 \\
& Ti-Ti (6) & 0.703 & 0.00191 & 2.99781 \\
& Ti-N-Ti-N (3) & 0.703 & 0.00514 & 4.14660 \\
\hline Wet & Ti-N (3) & 0.955 & 0.00397 & 2.10830 \\
& Ti-Ti (6) & 0.955 & 0.00141 & 3.03220 \\
& Ti-N (6) & 0.955 & 0.00512 & 3.77450 \\
\hline
\end{tabular}




\begin{tabular}{|c|c|c|c|c|}
\hline Electrode & $\begin{array}{c}\text { Scattering path \& } \\
\text { N }\end{array}$ & $\begin{array}{l}\text { Amplitude } \\
\qquad \mathbf{S}_{0}{ }^{2}\end{array}$ & $\begin{array}{c}\text { Bond strength } \\
\qquad\left(\sigma^{2}\right)\end{array}$ & $\begin{array}{c}\text { Distance from Ti R } \\
(\dot{\mathbf{A}})\end{array}$ \\
\hline $0 \mathrm{~V}$ & $\begin{array}{l}\text { Ti-N (3) } \\
\text { Ti-Ti (6) } \\
\text { Ti-N-Ti-N (3) }\end{array}$ & $\begin{array}{l}0.832 \\
0.832 \\
0.832\end{array}$ & $\begin{array}{l}0.00184 \\
0.00153 \\
0.00573\end{array}$ & $\begin{array}{l}2.05137 \\
2.99025 \\
4.10119\end{array}$ \\
\hline $0.2 \mathrm{~V}$ & $\begin{array}{l}\text { Ti-N (3) } \\
\text { Ti-Ti (6) } \\
\text { Ti-N-Ti-N (3) }\end{array}$ & $\begin{array}{l}0.926 \\
0.926 \\
0.926\end{array}$ & $\begin{array}{l}0.00004 \\
0.00255 \\
0.00390\end{array}$ & $\begin{array}{l}2.06073 \\
2.99493 \\
4.10213\end{array}$ \\
\hline$-0.2 \mathrm{~V}$ & $\begin{array}{l}\text { Ti-N (3) } \\
\text { Ti-Ti (6) } \\
\text { Ti-N-Ti-N (3) }\end{array}$ & $\begin{array}{l}0.752 \\
0.752 \\
0.752\end{array}$ & $\begin{array}{l}0.00107 \\
0.00045 \\
0.00321\end{array}$ & $\begin{array}{l}2.05940 \\
2.98465 \\
4.07087\end{array}$ \\
\hline $0.6 \mathrm{~V}$ & $\begin{array}{l}\text { Ti-N (3) } \\
\text { Ti-Ti (6) } \\
\text { Ti-N-Ti-N (3) }\end{array}$ & $\begin{array}{l}0.917 \\
0.917 \\
0.917\end{array}$ & $\begin{array}{l}0.00123 \\
0.00091 \\
0.00389\end{array}$ & $\begin{array}{l}.07266 \\
3.00772 \\
4.10476\end{array}$ \\
\hline$-0.5 \mathrm{~V}$ & $\begin{array}{l}\text { Ti-N (3) } \\
\text { Ti-Ti (6) } \\
\text { Ti-N-Ti-N (3) }\end{array}$ & $\begin{array}{l}1.074 \\
1.074 \\
1.074\end{array}$ & $\begin{array}{l}0.00432 \\
0.00487 \\
0.00553\end{array}$ & $\begin{array}{l}2.07050 \\
2.99852 \\
4.10117\end{array}$ \\
\hline
\end{tabular}




\section{References}

(1) Djire, A.; Wang, X.; Xiao, C.; Nwamba, O. C.; Mirkin, M. V.; Neale, N. R. Basal Plane Hydrogen Evolution Activity from Mixed Metal Nitride MXenes Measured by Scanning Electrochemical Microscopy. Adv. Funct. Mater. 2020, 116, 2001136.

(2) Djire, A.; Bos, A.; Liu, J.; Zhang, H.; Miller, E. M.; Neale, N. R. Pseudocapacitive Storage in Nanolayered $\mathrm{Ti}_{2} \mathrm{NT}_{\mathrm{x}}$ MXene Using Mg-Ion Electrolyte. ACS Appl. Nano Mater. 2019, 2 , $2785-2795$.

(3) Djire, A.; Zhang, H.; Liu, J.; Miller, E. M.; Neale, N. R. Electrocatalytic and Optoelectronic Characteristics of the Two-Dimensional Titanium Nitride $\mathrm{Ti}_{4} \mathrm{~N}_{3} \mathrm{~T}_{\mathrm{x}}$ MXene. ACS Appl. Mater. Interfaces 2019, 11, 11812-11823.

(4) Ravel, B.; Newville, M.; IUCr. ATHENA, ARTEMIS, HEPHAESTUS: Data Analysis for X-Ray Absorption Spectroscopy Using IFEFFIT. J. Synchrotron Rad. 2005, 12, 537-541. 